DOI 10.37882/2223-2982.2021.07.36

\title{
ХУДОЖЕСТВЕННЫЙ ТЕКСТ КАК ОБЪЕКТ ЛИНГВИСТИЧЕСКОГО АНАЛИЗА
}

\section{LITERARY TEXT AS AN OBJECT OF LINGUISTIC ANALYSIS}

S. Trotciuk

Summary: The article reveals the content of the notion «literary text», which is becoming more and more widespread in linguistics. The article presents different points of view on the definition of the term «literary text» as the essence and object of linguistic analysis. In the study from the text - to the subtext, from the meaning - to the meaning of aesthetic and artistic information is semantically derived from the entire text as a structural, semantic and communicative whole, stimulating the reader. Special attention is paid to the actual features of the literary text, its communicative nature.

The methodological basis of this article is the method of contextual analysis and the elements of linguistic and stylistic interpretation of literary text in their unity.

The novelty of the study lies in the fact that the purpose of linguistic analysis of the text is to identify the paradigm of the author's meanings and describe the mechanisms of their generation. In addition, the differences of the literary text, its features, from other types of texts are shown, for example, in the fact that the language of literary texts is different.

Keywords: syntagmatically, integration, connectivity, integrity, communication, interpretability, linguisticlabel analysis, extravagent, conceptuality.

\author{
троцюк Светлана Николаевна \\ к.филол.н., дочент, Российский государственный \\ гидрометеорологический университет \\ svetlana.trocuk@mail.ru
}

Аннотация: Статья раскрывает содержание понятия «художественный текст», которое получает все более широкое распространение в лингвистике. В статье приводятся разные точки зрения на определение термина «художественный текст» как сущности и объекта лингвистического анализа. При исследовании от текста - к подтексту, от значения - к смыслу эстетико-художественная информация семантически выводится из всего текста как структурно-смыслового и коммуникативного целого, стимулирующего деятельность читателя. Особое внимание уделяется актуальным признакам художественного текста, его коммуникативной природе.

Методологическую базу данной статьи представляет метод контекстологического анализа и элементы лингвостилистической интерпретации художественного текста в их единстве.

Новизна исследования заключается в том, что цель лингвистического анализа текста состоит в выявлении парадигмы авторских смыслов и описания механизмов их порождения. Кроме того, показаны отличия художественного текста, его признаков, от текстов других типов, например, в том, что язык художественных текстов иной.

Ключевые слова: синтагматичность, интегративность, связность, целостность, коммуникативность, интерпретируемость, лингвосмысловой анализ, экстрасвязность, концептуальность.

Связность текста выступает как результат взаимодействия нескольких факторов; логического, собственно лингвистического, коммуникативного и композиционного.

Она, как отмечают авторы книги «Лингвистический анализ художественного текста» «в большей степени лингвистична, обусловлена линейностью компонентов текста, то есть /.../ синтагматична» [1, с. 57]. Прежде всего она обеспечивается опорой на типизированные средства - строевые единицы, но распространяется и на другие уровни текстовой структуры, в том числе на лексику.

По мнению Н.С. Болотновой, «в основе связности текста лежит повтор, проявляющийся на разных его уровнях» [6, с. 33]. При этом связность однонаправлена: «интенциональность - основа интрасвязности, то есть внутренней смысловой связи; синтагматичность - причина экстрасвязности (выделено нами - С.Т.), проявляющейся во внешне выраженном сочетании букв, звуков, 
слов, предложений и т.п.» [1, с. 57]. Семантика текста может быть представлена как «фактор, жестко предопределяющий его связность» [1, с. 33].

Таким образом, связность текста перерастает в интегративность, структурированность.

Интегративность текста - это «ориентация всех элементов текстовой структуры на синтез - на воплощение содержательного плана текста, организованного авторской интенцией, его конкретными целями и мотивами» [6, с. 35]. Нам кажется, что модели связности художественного текста, предлагаемые 3.Я. Тураевой, - это, скорее, модели интегративности. Исследователь выделяет три модели связных текстов:

- статические модели, основанные на субституции, где главное место занимают межфразовые связи и отношения;

- динамические модели (ассоциативные модели), ориентированные на получателя, в их основе лежит «концепция открытости текста»;

- иртертекстуальные модели, вводящие текст в культурный контекст; при этом происходит «раскрытие текста в бесконечность, где каждый текст выступает как интертекст, а другой текст существует в нем на разных уровнях» [24, с. 6-7].

«Внутренняя» структурированность текста приводит к тому, что «механическая сумма составляющих его элементов, и "отдельность" этих элементов теряет абсолютный характер: каждый из них реализуется лишь в отношении с другими элементами и к структурному целому всего текста» [11, с. 11].

Результатом связности и интегративности текста ставится его целостность. «Целостность - это некоторая характеристика результата восприятия внутренне связанного текста, а сама связь - это средство, позволяющее получить данную характеристику» [15, с. 27]. 3. Я. Тураева определяет целостность как «невыводимость свойств всего объекта только из свойств отдельных элементов; неравенство сумме их свойств» $[25$, с. 56].

«За каждым текстом стоит система языка» [2, с. 299]. Суть вопроса о понятии «целостности»- в изучении особенностей перехода системы языка в целостную структуру текста. При этом важно среди элементов художественного целого определить такой, который, воплощая в себе качество художественности, одновременно был бы и главным из системообразующих элементов. Этим элементом, может быть ключевое слово: во-первых, оно в силу особой содержательной нагрузки и активной формообразующей функции, может выступать формально-содержательной основой всей художественной системы; во-вторых, может «осуществлять свою "отдельность", оставаясь связующим центром всех элементов системы» [12, с. 18].

Целостность текста имеет и психолингвистическую интерпретацию. «Во всяком тексте - писал Н.И. Жинкин, если он относительно закончен и последователен, высказана одна основная мысль, один тезис, одно положение. Все остальное подводит к этой мысли, развивает ее, аргументирует, разрабатывает» [10, с. 17].

По Н.В. Рафиковой, целостность - это «соотнесенность текста с одним (простым или сложным) объектом понимания, как некоторое проекционное состояние, возникшее при взаимодействии текста и читающего» [20, с. 53]. В понятии «проекция» находит свое выражение вариативность понимания: она тесно связана с «константными смыслами, общими для автора и читателя, без которых понимание превратилось бы в непонимание из-за произвольной интерпретации исходного текста» [Там же].

По мнению авторов книги «Лингвистический анализ художественного текста», целостность (или цельность) текста обладает ситуативностью, так как она обеспечивается не только «денотативным пространством текста», но и «конкретной ситуацией его восприятия: кто воспринимает текст, где, когда, зачем?» [1, с. 56]. Таким образом, эта важнейшая категория текста коммуникативна по своей сути.

«Художественный текст можно определить как коммуникативно направленное вербальное произведение, обладающее эстетической ценностью, выявленной в процессе его восприятия», а коммуникативность рассматривать как «ключевое совокупное качество текста, определяющее остальные» [6, с. 31].

Восприятие текста состоит, по мнению Л.А. Новикова, из двух этапов: «непосредственного восприятия материальных знаков; перехода от образа языкового знака как материального объекта к образу его содержания. Оба эти этапа сопровождаются осмыслением, пониманием воспринимаемого материала» [15, с. 35]. Вместе с тем понимание текста - это «сложный мыслительный процесс, в результате которого происходит активное преобразование словесной формы текста» [15, с. 46]. Особое место отводится декодированию «импликатур», т.е. «различных смысловых структур, не эксплицированных, невыраженных, восприятие которых невозможно без "фоновых" тезаурусных знаний» [5, с. 13].

«Образ читателя присутствует в сознании автора на разных этапах порождения текста, определяя коммуникативную стратегию произведения и проецируя коммуникативный эффект» [5, с. 16]. При рассмотрении коммуникативного взаимодействия «автор - текст - читатель» семантически структуру текстовой деятельности, по мнению Л.Г. Бабенко, можно представить следующим об- 
разом (компонент «исследователь» включен нами - С.Т.): [1, c. 14]

Мы имеем дело в рамках художественной коммуникации по меньшей мере с двумя смысловыми вариантами текста: текстом автора, - «дирижера», который управляет процессом развития темы» [21, с. 251], и текста читающего, «идеального адресата, то есть предполагаемого читателя, ход, характер и глубина интерпретаторской деятельности которого соотносимы с набором успешной коммуникации, задаваемых каждому конкретному художественному тексту» [7, с. 14].

Автор и читатель вступают в особого рода диалог, идеальным результатом которого должна быть «гармонизация общения»/Н.С. Болотнова/, то есть предельное сближение «текста читателя» с «текстом автора». «Текст», «текст произведения» невозможны без определения их автора, его стиля, а «смысл текста» и «смысл произведения» - без читателя (или исследователя), поэтому «эффективность творческого диалога автора и читателя во многом определяется силой художественного слова, его коммуникативными возможностями и характером эстетической актуализации в тексте» [5, с. 52].

Эту позицию поддерживает и В.В. Степанова. Субъективная организация художественного текста может быть выявлена, по мнению учёного, при исследовании его в двух направлениях. Одно из них имеет своим объектом внутритекстовые ситуации общения, то есть диалогические и монологические фрагменты и их лексическую структуру. Однако, эти открытые коммуникативные формы, обладая особой функциональной нагруженностью в прозаическом художественном тексте, занимают лишь небольшую часть его пространства. Поэтому значимым является второе направление, которое соотнесено с «внетекстовыми» субъектами литературной коммуникации - автором и читателем. Это направление и рассматривает лексическую организацию художественного текста с позиций гармонизации их общения [22, с. 98].

В языковой картине мира коммуникантов лексикон обладает способностью называть явления реальной или художественной действительности с помощью лексических единиц, закреплённых в практике речевого общения. Как пишет И.М. Берман, «на уровне осознания читающий перерабатывает смысл, передаваемый прежде всего лексическими составляющими текста. Переработка грамматической информации поддерживает и модифицирует смысловое восприятие информации лексической» [3, с. 27].

Традиционно «понимание текста» рассматривается как «процесс установления его (текста) смысла, который как бы "закодирован" в тексте автором» [13, с. 3]. В когнитивном аспекте понимание текста - это «достижение в сложной перцептивно-мыслительной деятельности по смысловой переработке речевой информации в высшей ступени, характеризующееся созданием у воспринимаемого субъекта целостного образного смыслового содержания сообщения - концепта текста» $[4$, с. 5].

Представляя текст как сложное единство трех планов: «языкового оформления, смысловой структуры и предметного содержания» [4, с. 5], для установления степени адекватности понимания текста нужно сравнить смысловое содержание передаваемого коммуникатором и воспринятого реципиентом текста: во-первых, степень полноты и точности отражения в сознании читателя предметной ситуации, описанной в тексте (что соответствует уровню денотативного пространства текста), во-вторых, глубину проникновения в концептуальное пространство текста.

Под концептуальным пространством художественного текста авторы книги «Лингвистический анализ художественного текста» понимают «индивидуальноавторский способ восприятия и организации мира, то есть частный вариант концептуализации мира» [1, с. 82], цельную концептосферу текста, ключевой концепт которой «представляет собой ядро индивидуально-авторской художественной картины мира» [Там же].

Большое значение для формирования концепта имеют повторяющиеся в тексте слова - «ключевые слова» [1, с. 83], занимающие центральное место в лексической структуре художественного текста.

В языковой картине мира коммуникантов лексикон обладает способностью называть явления реальной или художественной действительности с помощью лексических единиц, закрепленных в практике речевого общения. Как пишет И.М. Берман, «на уровне осознания читающий перерабатывает смысл, передаваемый прежде всего лексическими составляющими текста. Переработка грамматической информации поддерживает и модифицирует смысловое восприятие информации лексической» $[3$, с. 27].

В процессе порождения текста и его восприятия велика роль «коммуникативного потенциала слов, детерминированного речевой практикой», т.е. «закрепленной в сознании носителей языка /.../ потенциальной способности слов прямо или косвенно соотноситься с определенными ситуациями общения» [6, с. 27].

По мнению Е.Г. Биевой, факторы, влияющие на результат понимания, подразделяются на объективные и субъективные. Объективные факторы присущи воспринимаемому вербальному материалу: производны от содержательной структуры текста [4, с. 5]. Так, тексты произведений Н.В. Гоголя, безусловно, относятся к сложным 
и по содержанию, и по языковой форме: «плотность» гоголевского слова приближает его прозу к поэзии. К субъективным факторам, характеризующим языковой и когнитивный уровень читателя относится специфика индивидуальной системы знаний, языковых и внеязыковых, тезаурусных.

А.А. Потебня ввел разграничение «ближайшего» и «дальнейшего» значения слова [19, с. 217-218]. В современной лингвистике эти термины соответствуют узуальному, языковому и уникальному, индивидуальному началам в семантике художественного слова.

Восходящее к В. Гумбольдту и А.А. Потебне учение о нетождественности «значения говорящего» и «значения слушающего /читающего» создает проблему интерпретируемости художественного текста.

Интерпретируемость - это универсальное качество текста, причем художественный текст принципиально допускает множественность интерпретаций. Это обусловлено «уникальности художественного текста как психолого-эстетического феномена, ибо он создается автором для выражения своих индивидуальных представлений о мире, знаний о мире» с использованием единых для участников литературной коммуникации языковой системы и «направлен читателю» [1, с. 63]. При этом и автор, и читатель по-своему интерпретируют одни и те же языковые знаки, входящие в структуру художественного текста. Совпадение ближайших значений слов совсем не предполагает совпадения дальнейших значений.

При этом понимание языкового выражения, усвоение его смысла предполагает построение структуры смыслов, которые, по мнению Р.И. Павилёниса, рассматриваются в качестве «интерпретаторов» и «анализаторов» $[16$, с. 102].

С учётом «фундаментального принципа интерпретации» интерпретируемый объект является базой для развития концептов, которая интегрируется другими концептуальными системами. Такая интерпретация объектов в данной системе есть «построение в ней информации об определённом мире» [16, с. 210]. Иными словами, осмысленность языковых выражений рассматривается как «вопрос о возможности построения определённой концептуальной системы» [16, с. 207]. Языковое выражение можно считать осмысленным в данной системе, если соответствующая этому выражению концептуальная структура интерпретируется множеством её концептов.

Результатом этого процесса является понимание языкового выражения носителем языка. В силу того, что сущность интерпретации состоит в приписывании определённого смысла объекту, возможны различия в интерпретации одного и того же выражения, то есть не- сколько интерпретаций. При этом и автор, и читатель посвоему интерпретируют одни и те же языковые знаки, входящие в структуру художественного текста. Совпадение ближайших значений слов совсем не предполагает совпадения дальнейших значений.

Таким образом, понимание состоит в интерпретации репрезентантов (языковых и неязыковых) на определённом уровне концептуальной системы, причём интерпретация может быть как истинной, так и ложной.

«Вариативность, деривационная подвижность, ассоциативность и активность в текстопорождении являются условиями его (текста) существования как автономной структуры» [18, с. 131]. Возможности интерпретации текста обеспечиваются тем, что инвариантные характеристики заложены в тексте в двух измерениях: линейном - это «построение, проявляющееся в лексических и синтаксических закономерностях, в типе повествования и форме изложения, а также в определенном соположении эпизодов и глав» $[21$, с. 6], и объемном - это «способ воплощения универсальных и индивидуальных смыслов текста с использованием для выражения конкретных смысловых элементов композиционно-синтаксических, синтаксических и лексических уровней» [21, с. 7]. Пересечение «ядерных смыслов автора» и воспринимающего происходит благодаря тому, что «ядро» проекции текста остается константным при варьировании «периферии». Множественность образов «задает то семантическое пространство, в пределах которого возможно варьирование, не переходящее в произвольную интерпретацию. Воспринимаемый направляет фокус своего внимания на тот или иной ядерный смысл /.../, происходит перестановка акцентов внутри «ядерного» семантического пространства /.../» [17, с. 54].

Изучая вариативность как «несоответствие между мыслью передающего и воспринимающего информацию», Н.В. Рафикова обращает внимание на роль ключевых слов, которые являются «первыми опорными элементами, направляющими развитие индивидуальной проекции по спирали». Возбуждаемое ими «поле предлагает «набор вариантов», из которых «читатель выбирает некоторое число доминант, может быть только одно». Эти доминанты, в свою очередь, становятся «опорными элементами следующего уровня и возбуждают свое поле, которое предлагает свой набор элементов и т.д.» $[20$, c. 103$]$.

Таким образом организованная структура текста обладает свойством регулятивности, т.е. способностью «управлять познавательной деятельностью читателя» [8, с. 4].

Текст способен оказывать воздействие на чувства читателя и возбуждать реакции эстетического порядка. Эту функцию художественного текста Ю.П. Солодуб 
считает определяющей, не случайно он определяет художественный текст как «сверхфразовое единство, характеризуемое общностью идейно-тематического содержания и эстетическим воздействием на читателя как своей основной функцией» [23, с. 46]. По мнению О.И. Москальской, художественное произведение - это такое «речевое произведение, которое является прежде всего эстетической категорией, и его коммуникативное задание реализуется через эстетическую функцию» [14, с. 14].

Психолингвистические закономерности читательской интерпретации в основе своей действительны и для интерпретационной деятельности читателя. «Событие жизни текста, то есть его подлинная сущность, всегда развивается на рубеже двух сознаний, двух субъектов. Стенограмма гуманитарного (= исследовательского С.Т.) мышления - это всегда стенограмма диалога особого вида: сложное взаимоотношение текста (предмет изучения и обдумывания) и создаваемого обрамляющего контекста (вопрошающего, возражающего и т.п.), в котором реализуется познающая и оценивающая мысль ученого. Это встреча двух текстов - готового и создаваемого реагирующего текста /.../» [2, с. 301].

Первое, собственно читательское восприятие художественного текста для исследователя оказывается лишь исходным, основанным на интуиции. Исследовательская интерпретация обязательно предполагает не только повторное, но и многократное обращение к тексту, причем уже не интуитивно-читательское, а с применением специальных исследовательских методов и приемов. Н.А. Купина выделяет два направления лингвосмыслового анализа художественного текста:
1. от содержательной (= концептуальной) гипотезы к ее подтверждению через анализ языковой организации текста;

2. от языковых особенностей текста к формулировке его идейно-тематических характеристик [12, с. 10].

Думается, лишь последовательное соединение этих направлений может обеспечить результативность лингвистического анализа художественного текста. Методика анализа ключевых слов в соединении с другими, содержательно и ассоциативно связанными с ними, - один из приемов такого анализа, позволяющий выйти на уровень понимания художественного произведения в его целостности.

Второй путь, на наш взгляд, больше соответствует понятию лингвистического анализа художественного текста. Методика ключевых слов - один из приемов такого анализа, позволяющий выйти на уровень анализа целостного текста художественного произведения.

Основной единицей его смысловой структуры является концептуально значимый смысл, непосредственно соотносимый с концепцией (содержанием) текста в целом. Его главным свойством является "модальная оболочка, в которую включается «предметно-фактическая информация» и которая проявляется «в актуальных (для концепции денного текста) модальных оппозициях» [9, с. 59].

Как показывают исследования, «поворот лингвистики к целостному тексту как объекту исследования, а также рассмотрение его в теоретической среде антропологической лингвистики и когнитологии поставили учёных перед необходимостью исследования концептуального смысла текста» [1, с. 77].

\section{ЛИТЕРАТУРА}

1. Бабенко Л.Г., Васильев И.Е. и др. Лингвистический анализ художественного текста. Екатеринбург: Изд-во Урал. ун-та, 2000. 532 с.

2. Бахтин М.М. Эстетика словесного творчества. М.: Искусство, 1986. 445 с.

3. Берман И.М. Текст и его структура. М.: Флинта, 1992.210 с.

4. Биева Е.Г. Факторы, влияющие на понимание текстов (на материале детской речи): Автореф. дис. канд. филол. наук / Ин-т языкознания АН СССР. М., 1984. $18 \mathrm{c}$.

5. Болотнова Н.С. Гармонизация общения и лексическая структура художественного текста. СПб: Образование, 1992. 55 с.

6. Болотнова Н.С. Коммуникативные универсалии и их лексическое воплощение в художественном тексте // Филологические науки. 1992 . № 4.

7. Болотнова Н.С. Основы теории текста. Томск: изд-во Том. пед. ун-та, 1999.98 с.

8. Болотнова Н.С. Лексическая структура художественного текста в ассоциативном аспекте. Томск, 1994. 210 с.

9. Дымарский М.Я. Проблемы текстообразования и художественный текст (на материале русской прозы XIX-XX вB.). СПб: Издательство СанктПетербургского университета, 1999. 240 с.

10. Жинкин Н.И. Развитие письменной речи учащихся III - VII классов // Изв. АПН РСФСР. М., 1956. Вып.78. 124 с.

11. Зубова Л.В., Снегирева М.Л. Анализ художественного текста по ключевым словам // Коммуникативная и поэтическая функция художественного текста. Воронеж: Изд-во Воронеж, ун-та, 1982. 179 с.

12. Купина Н.А. Лингвистический анализ художественного текста. М: Просвещение, 1980.78 с.

13. Лотман Ю.М. Анализ поэтического текста. Л.: Издательство «Просвещение», ленинградское отделение, 1972. 272 с.

14. Москальская 0.И. Грамматика текста. - М.: Высшая школа, 1981. 183 с. 
15. Новиков А.И. Семантика текста и ее формализация. М.: Наука, 1983. 216 с.

16. Павилёнис Р.И. Проблема смысла: Современный логико-философский анализ языка. - М.: Мысль, 1983. 286 с.

17. Пищальникова В.А. Проблемы лингвоэстетического анализа художественного текста. Барнаул: Алтайский государственный университет, 1984.320 с.

18. Пищальникова В.А. Проблемы смысла художественного текста. Психолингвистический аспект. Новосибирск: Изд-во Новосиб. ун-та, 1992. 131 с.

19. Потебня А.А. Ударение. Киев: Наук. думка, 1973. 167 с.

20. Рафикова Н.В. Вариативность понимания художественного текста в свете данных психолингвистического эксперимента // Слово и текст: Актуальные проблемы психолингвистики. Тверь: Тверской госун-т, 1994. 160 с.

21. Рафикова Н.В. «Ядро» проекции текста как инвариант, обеспечивающий взаимопонимание между автором и читателем // Актуальные проблемы лингвистики и методики обучения иностранным языкам. Тверь: Тверской гос. ун-т, 1992. 264 с.

22. Степанова В.В. Лексическая структура художественного текста в коммуникативном аспекте // Актуальные проблемы функциональной лексикологии. СПб.: Изд-во СПбГУЭФ, 1997. 280 с.

23. Солодуб Ю.П. Текстообразующая функция символа в художественном произведении // Филологические науки. 2002. № 2.

24. Тураева 3.Я. Лингвистика текста. Лекции. СПб: Образование, 1993. 38 с.

25. Тураева 3.Я. Лингвистика текста. Текст: структура и семантика. М.: Просвещение, 1986. 127 с.

(с) Троцюк Светлана Николаевна (svetlana.trocuk@mail.ru).

Журнал «Современная наука: актуальные проблемы теории и практики»

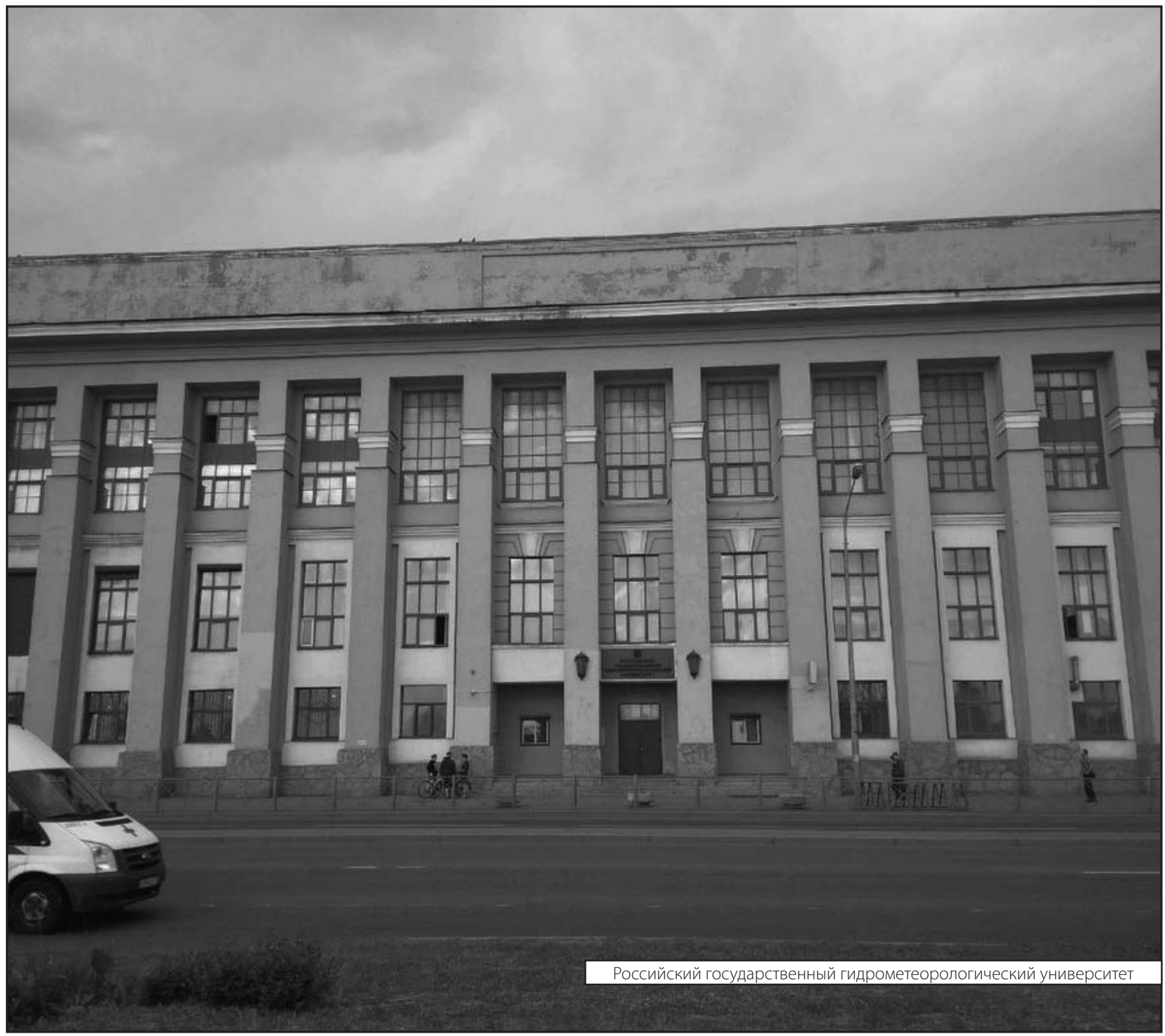

